\title{
Inhibition of active autophagy induces apoptosis and increases chemosensitivity in cholangiocarcinoma
}

\author{
Yu-Jie Hou, ${ }^{*}$, Li-Wei Dong*,1, Ye-Xiong Tan*,1, Guang-Zhen Yang ${ }^{1}$, Yu-Fei Pan ${ }^{1}$, Zhong Li ${ }^{1}$, Liang Tang ${ }^{1}$, \\ Min Wang ${ }^{1}$, Qing Wang ${ }^{1}$ and Hong-Yang Wang ${ }^{1,2}$
}

Intrahepatic cholangiocellular carcinomas (ICCS) are usually fatal neoplasms originating from bile duct epithelia. However, many cholangiocarcinoma cells are shown to be resistant to chemotherapeutic drugs, which induce cell apoptosis. The role of autophagy and the therapeutic value of autophagy-associated genes are largely unknown in ICC. Here, we showed that autophagy was activated in nutrient starvation and xenograft cholangiocarcinoma cells. Furthermore, expression of autophagic genes and their autophagic activity were higher in clinical ICC specimens than that in normal cholangiocytes separated by laser capture microdissection. Inhibition of autophagy by autophagy inhibitors or siRNA, cholangiocarcinoma cells showed detention of proliferation and increase of apoptosis during nutrient starvation. In addition, autophagy inhibitor treatment or knockdown of beclin 1 suppressed tumor growth and sensitized ICC cells to chemotherapeutic agent-induced cell death. In conclusion, our data showed that autophagy is activated in ICC, and inactivation of autophagy may lead to cell apoptosis and enhance chemotherapy sensitivity.

Laboratory Investigation (2011) 91, 1146-1157; doi:10.1038/labinvest.2011.97; published online 6 June 2011

KEYWORDS: apoptosis; autophagy; beclin 1; chemotherapy sensitivity; cholangiocellular carcinomas

Intrahepatic cholangiocellular carcinoma (ICC) is a malignant neoplasm originating from epithelium of the biliary tree with high mortality. ${ }^{1}$ ICC accounts for $5-30 \%$ of all primary liver malignancies, and its incidence has been increasing over the last several decades. ${ }^{2}$ The mortality from intrahepatic cholangiocarcinoma is very high, with the 5-year survival rates being $<15-20 \%$ in most series. ${ }^{3,4}$ However, the exact molecular mechanisms of biliary epithelium malignant transformation are not well understood. Despite improved diagnostic and operative techniques, the prognosis of ICC remains poor. ${ }^{5}$ Indeed, ICC is a type of cancer highly resistant to conventional antineoplastic medicines, ${ }^{4}$ which is partially attributed to the property of insensitivity to cell death induced by cytotoxic agents. It is well known that the avoidance of apoptosis is one of the hallmarks of cancer cells, ${ }^{6}$ and that failure to induce apoptosis by anticancer treatments contributes to chemotherapeutic failure and tumor progression. Although autophagy, an alternative caspase-independent cell death program, ${ }^{7}$ is thought to be used for cancer treatment, its underlying molecular mechanism is still controversial in antineoplastic therapy and also in tumor progression.

Autophagy is a conserved catabolic process by which cells themselves digest their organelles. ${ }^{8}$ Autophagy has emerged as a homeostatic mechanism regulating the turnover of long-lived or damaged proteins and organelles, and buffering metabolic stress induced under starvation conditions by recycling intracellular constituents. ${ }^{9}$ Autophagosomes engulfing organelles then fuse with lysosomes and mature into autolysosomes. Autophagic processes have been well characterized in yeast, and $>30$ autophagy-related genes that encode the proteins executing autophagy have been identified in the field of yeast genetics. ${ }^{6,7}$ The amino acids and fatty acids generated by autophagic degradation are used by the tricarboxylic acid cycle to produce ATP. Although previous findings strongly suggest that autophagy contributes to sustainable cell survival, antitumorigenic roles of autophagy have been also mentioned. ${ }^{8}$

\footnotetext{
'International Cooperation Laboratory on Signal Transduction, Eastern Hepatobiliary Surgery Institute, The Second Military Medical University, Shanghai, People's Republic of China and ${ }^{2}$ State Key Laboratory of Oncogenes and related Genes, Shanghai Cancer Institute, Renji Hospital, Shanghai Jiaotong University School of Medicine, Shanghai, People's Republic of China

Correspondence: Professor H-Y Wang, MD, International Cooperation Laboratory on Signal Transduction, Eastern Hepatobiliary Surgery Institute, The Second Military Medical University, 225 Changhai Road, Shanghai 200438, People's Republic of China.

E-mail: hywangk@vip.sina.com

*These authors contributed equally to this work.

Received 28 December 2010; revised 25 April 2011; accepted 27 April 2011
} 
Autophagy has roles in protecting cells against shortage of nutrients. Cells supply amino acids from self-digested organelles as an alternative energy source for their survival. ${ }^{6,9}$ This function of autophagy seems ideal to foster cancer cells to survive in an unfavorable starved environment. However, the physiologic relevance of autophagy in tumor formation and progression is still not clear. Although activation of autophagy is in multiple human primary cancers, the biological role of autophagy in control of cholangiocarcinoma growth has not been established. In this study, we performed in vitro and in vivo studies to address the role of autophagy in cholangiocarcinoma cell growth, apoptosis and chemotherapy sensitivity by molecular inhibitors and antisense depletion of autophagy essential gene expression, intercepting regular autophagy process, to evaluate the role of autophagy in the effect of chemotherapy of human intrahepatic cholangiocarcinoma.

\section{MATERIALS AND METHODS Cell Lines}

Human cholangiocarcinoma cell lines QBC939, RBE and HCCC9810 cells were purchased from XiangYa Central Experiment Laboratory and cultured in RPMI1640 medium supplemented with 15\% NCS (Gibco, 16010-159). The cholangiocarcinoma cell lines RBE and HCCC9810 are both derived from intrahepatic cholangiocarcinoma, ${ }^{10,11}$ while QBC939 is derived from hilar. ${ }^{12}$ For starvation studies, these three cell lines were seeded in 12-well plates and incubated in medium without amino acids. The cells were then washed with PBS, and cultured in Earle's Balanced Salt Solution (EBSS; Sigma-Aldrich, E2888) at $37^{\circ} \mathrm{C}$ for the indicated times.

\section{Reagents}

Wortmannin and 3-methyl adenine (3-MA) were purchased from Sigma (W1628, M9281). Wortmannin was used at $5 \mu \mathrm{M}$ and 3-MA was used at $10 \mathrm{mM} .{ }^{13,14}$ Cisplatin and doxorubicin were purchased from Shandong Qilu Pharmaceutical Product Factory (H37021358, H33021980). Cisplatin concentration was $6 \mu \mathrm{g} / \mathrm{ml}$ and doxorubicin was used at $10 \mu \mathrm{g} / \mathrm{ml} .^{15,16}$ Hoechst 33342 and propidium iodide (PI) were purchased from Sigma (14533, P4170).

\section{Patients Samples}

The 41 primary intrahepatic cholangiocarcinoma specimens used in real-time PCR studies were randomly collected from the patients undergoing curative resection in Eastern Hepatobiliary Surgery Hospital in Shanghai, China from 2002 to 2007. The specimens used for immunohistochemistry (IHC) were routinely processed, formalin fixed and paraffin embedded. Twenty-four frozen tissue samples from above patients were used for western analysis and 50 cases for IHC assay. Five of normal bile vessel tissue were obtained by laser capture microdissection from frozen angioma specimens as described before. ${ }^{17}$ Informed consent was obtained from all patients before subsequent use of their resected tissues. The present study was performed in accordance with the ethical standards of the Helsinki Declaration in 1975, after approval of the local ethics committee.

\section{Production of Recombinant Adenovirus and Adenoviral Infection}

Production of recombinant adenovirus methods is as described previously. ${ }^{18}$ The synthesized oligonucleotides were as follows: Sibeclin1 forward, $5^{\prime}$-GATCCCCCAGTTTGGCAC AATCAATATTCAAGAGATATTGATTGTGCCAAACTGTTTT TA-3'; reverse, 5'-AGCTTAAAAACAGTTTGGCACAATCA ATA TCTCTTGAATATTGATTGTGCCAAACTGGGG-3' .

\section{RNA Isolation and Real-Time PCR}

Total RNA was extracted from frozen specimens using Trizol Reagent (Invitrogen, 15596-026). Total RNA ( $2 \mu \mathrm{g})$ was used for RT with oligo(dT) random primers of Promega RT kit according to the manufacturer's protocol. All quantitative real-time PCR reactions were performed in $1 \times$ Universal Master Mix (Applied Biosystems, 4367659) with gene-specific primers and probe on the ABI Prism 7300 Sequence Detection System, according to the manufacturer's instructions. The $18 \mathrm{~S}$ rRNA levels were quantified as internal control to normalize the expression of each gene. Each reaction was repeated independently at least three times.

\section{Western Blotting Assay}

Western blotting was performed as previously described. ${ }^{19}$ In brief, the tissues or cells were lysed in RIPA buffer and sonicated. Protein concentrations were measured by BCA (Thermo scientific, 23228). Proteins were loaded to standard SDS-PAGE gel and transferred to polyvinylidene difluoride membranes, which were detected with the primary antibodies: anti-LC3 rabbit polyclonal (dilution, 1:1000; Abcam, ab48394); anti-beclin 1 monoclonal (dilution, 1:1000; Santa Cruz, sc-48381); anti-Tubulin monoclonal (Santa Cruz, sc-58667) and anti-GADPH monoclonal (dilution, 1:1000; Cell Signaling, 2118), followed by a secondary antibody (IRDye800CW, 926-32210). The fluorescence density on PVD membranes were detected with LI-COR imaging system (LI-COR Biosciences, 9201-01).

\section{Immunohistochemistry}

Sections were deparaffinized through xylene and rehydrated with graded alcohol. Endogenous peroxidase was then blocked with $3 \% \mathrm{H}_{2} \mathrm{O}_{2}$ diluted in methanol for $20 \mathrm{~min}$ at room temperature. Antigen retrieval was performed by treating the slide in citrate buffer in a microwave for $10 \mathrm{~min}$. The slides were blocked in $1 \%$ bovine serum albumin and incubated with beclin 1 monoclonal antibody (Santa Cruz, sc-48381) at $4{ }^{\circ} \mathrm{C}$ overnight. After a brief wash in PBS, the slides were treated with goat anti-mouse (Santa Cruz, sc2031) for $30 \mathrm{~min}$ at $37^{\circ} \mathrm{C}$. After a brief wash in PBS, the slide was developed in $0.05 \%$ freshly prepared diaminobenzedine 
solution (DAB, Sigma, D8001) for $8 \mathrm{~min}$, and then counterstained with hematoxylin.

\section{Cell Proliferation, Cycle and Apoptosis Analysis}

Cell proliferation was detected by CCK- 8 assay. Cells were seeded $\left(5 \times 10^{3}\right.$ cells per well) in 96-well plates and cultured overnight at $37^{\circ} \mathrm{C}$, then exposed to drugs for indicated time and cell viability was measured using Cell Counting kit-8 at various time points according to the guidance of the manufacturer. Cell cycle analysis was assessed by staining with PI as described previously. ${ }^{20}$ Hoechst 33342 was applied to detect nuclear fragmentation characteristic of apoptosis as described previously. ${ }^{21}$ Treated cells were stained and examined under fluorescent microscopy. Apoptosis was also assessed by using an AnnexinV-FITC apoptosis detection kit (Invitrogen, V13241) according to the manufacturer's protocol.

\section{Detection of the Expression of Green Fluorescent Protein-LC3}

The green fluorescent protein (GFP)-human LC3 fusion protein expressing plasmid pEGFP-LC3 was kindly provided by Prof. Mujun Zhao (Institute of Biochemistry and Cell Biology, Chinese Academy of Sciences, Shanghai, People's Republic of China). QBC939 and RBE cells $\left(5 \times 10^{4}\right.$ per well) were seeded in six-well plates the day before transfection and $2 \mu \mathrm{g}$ of plasmid was transfected with FuGENER HD Transfection Reagent (Roche, 04709691001). GFP fusion proteins were observed under a laser scanning microscope system (PerkinElmer, UltraVIEWVoX). The percentage of GFP-LC3positive cells with GFP-LC3 punctate dots was determined from three independent experiments. The cells with more than five GFP-LC3 punctate dots were counted under blinded conditions. A minimum of 30 GFP-LC3-positive cells assessed from at least six random fields per sample were counted in triplicate per condition per experiment.

\section{Transmission Electron Microscopy}

Surgically resected tissue samples were fixed in ice-cold $2 \%$ glutaraldehyde and examined with a JEOL transmission electron microscope (JEM-1230) as described previously. ${ }^{22}$

\section{Xenograft Tumor Model in Nude Mice}

The xenograft model was described as before. ${ }^{23}$ The QBC939 cells were grown to subconfluency in complete medium. Viable cells $\left(2 \times 10^{6}\right.$ in $\left.\mathrm{PBS} / 100 \mu \mathrm{l}\right)$ were injected subcutaneously into the flanks of 4 -week-old nude mice. Two weeks after tumor cell inoculation, mice were divided randomly into groups and were given i.p. injections of either the drug vehicle DMSO (Sigma, D8414) or wortmannin (2 mg/ $\mathrm{kg})^{24,25}$ for 10 days or treated AdSi-beclin or AdSi-blank virus for 2 weeks by a way of multiple-center intratumor injection of $50 \mu \mathrm{l}$. Then, all mices were killed and the xenografted tumors were excised. All animals received human care according to the criteria outlined in the Guide for the Care and Use of Laboratory Animals, which was prepared by the National Academy of Sciences and published by the National Institutes of Health (publication 86-23; revised 1985).

\section{Statistical Analysis}

The data were expressed as means \pm s.d. Statistical analysis was performed by using Student's $t$-test or by one-way ANOVA followed by Dunnett's test for multiple comparisons. $P$-value $<0.05$ was considered significant.

\section{RESULTS}

\section{Nutrient Starvation and Xenograft-Induced Autophagy Activation in Cholangiocarcinoma Cell Lines}

Three cholangiocarcinoma cell lines, including QBC939, RBE and HCCC9810, were used to examine autophagy activation in nutrient starvation situation. These cells were cultured in amino-acid-deprived medium with or without the combination of 3-MA for $12 \mathrm{~h}$. The distribution of GFP-LC3 was determined by confocal fluorescent microscopy, and autophagosome-associated GFP-LC3 level was quantified (Figure 1a).

The GFP-LC3 fusion protein was observed as coarse dots in the cytoplasm of both QBC and RBE cells cultured in an amino-acid-deprived medium. While adding, 3-MA significantly inhibited GFP-LC3 dots formation in starvation cells. LC3-II was detected in cells cultured in amino-aciddeprived medium for $6,12,24,36$ and $48 \mathrm{~h}$. We found that the levels of LC3-II were significantly increased in cells from $12 \mathrm{~h}$ in amino-acid deprivation condition compared with non-starvation (Figure 1b). We then asked whether increased level of autophagy is also seen in cholangiocarcinoma during these cells form tumor in mice. We injected the three cell lines subcutaneously into flanks of nude mice, but only QBC cells can form tumor. In the QBC tumor, the ultrastructures of autophagy (autophagic vesicles) were visualized as double-membrane vacuoles in the cytoplasm under the transmission electron microscopy (Figure $1 \mathrm{cB}$ and $\mathrm{C})$, while in the free $\mathrm{QBC}$ cells few vacuoles was detected (Figure 1cA). The results indicated that nutrition deprivation may induce activation of autophagy that is involved in tumorigenesis.

\section{Autophagy Is Activated in Clinical Cholangiocarcinoma Specimen}

To investigate whether autophagy is also present in cholangiocarcinoma of patients, we detected autophagy in surgically resected cholangiocarcinoma tissues by transmission electron microscopy. The results revealed that there was rare vacuoles in normal bile duct epithelium (Figure 2aA) compared with ICC tissue (Figure $2 \mathrm{aB}$ and $\mathrm{C}$ ). Large membranous vacuoles were seen in the cytoplasm and some of the vacuoles resembled autophagosomes and contained remnants of degraded organelles, including mitochondria (Figure 2a). Next, we tested expression of full-length LC3-I and LC3-II using lysates from cholangiocarcinoma specimens. We found 
a
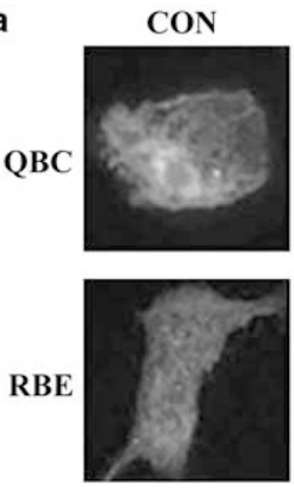
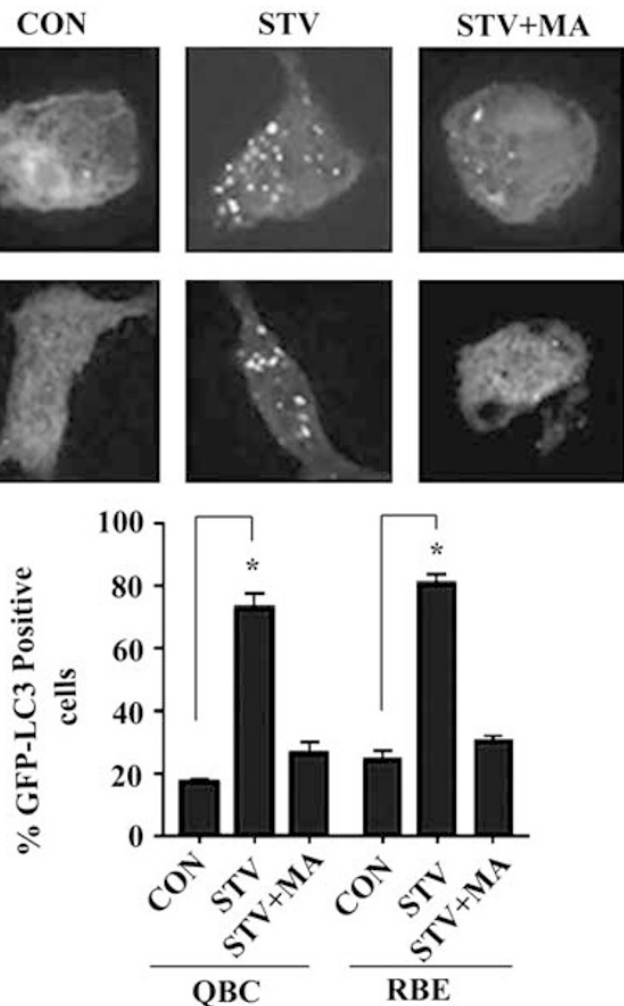

STV+MA

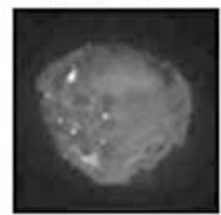

$\begin{array}{lllllll}\text { Starvation } & 0 & 6 & 12 & 24 & 36 & (\mathrm{hr})\end{array}$

QBC

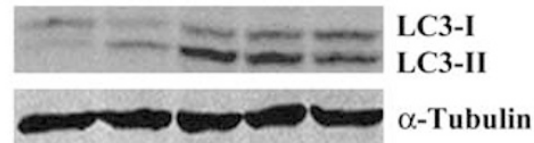

$\begin{array}{lllllll}\text { Starvation } & 0 & 6 & 12 & 24 & 36 & (\mathrm{hr})\end{array}$

RBE

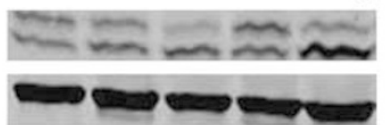

LC3-I

LC3-II

$\alpha$-Tubulin

$\begin{array}{lllllll}\text { Starvation } & 0 & 6 & 12 & 24 & 36 & (\mathrm{hr})\end{array}$

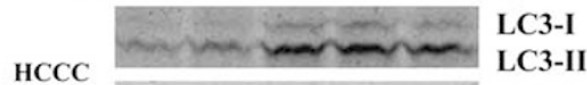

HCCC

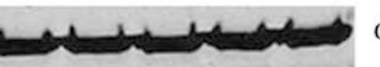

$\alpha$-Tubulin

C

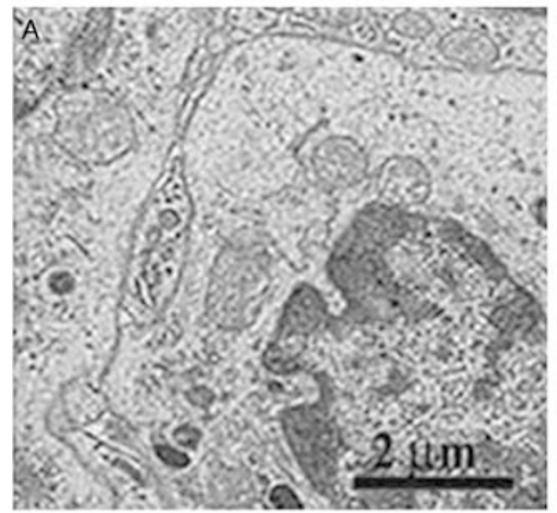

Free cell

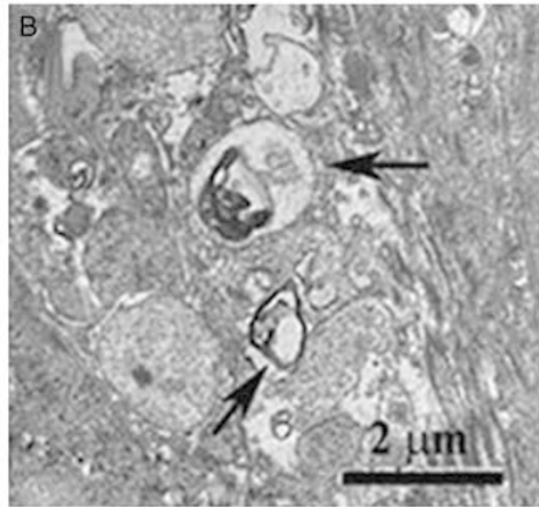

Tumor 1

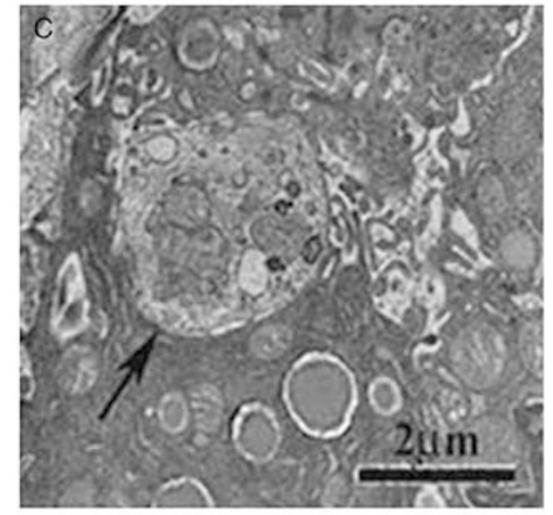

Tumor 2

Figure 1 Nutrient starvation and xenograft-induced autophagy activation in cholangiocarcinoma cells. (a) Representative confocal images of GFP-LC3 staining and quantitation of the GFP-LC3-positive cells with the GFP-LC3 dots in the two cell lines. QBC939 and RBE cells transiently transfected GFP-LC3 plasmids were incubated in EBSS with vehicle (PBS) or $10 \mathrm{mmol} / \mathrm{l}$ of 3-MA for $12 \mathrm{~h}$ and observed with the confocal fluorescent microscope. (b) Western blotting analysis LC3 expression on cholangiocarcinoma cells under starvation culture. Three cholangiocarcinoma cell lines were cultured in EBSS for indicated time, then total cell lysates were collected for western blotting to detect LC3 proteins. (c) Representative transmission electron micrographs of autophagosomes in xenografted tumors. QBC939 xenografted tumors in nude mice were examined by electron microscopy. Arrows denote autophagosomes. Results represent the mean \pm s.d. of combined data from three independent experiments. ${ }^{*} P<0.05$.

that 18 out of 24 cases presented high LC3-II expression (Figure $2 \mathrm{~b}$ ). The mRNA expression of autophagic relative genes (atg5, beclin 1) was evaluated in 41 primary intraheptic cholangiocarcinoma specimens. Almost all the autophagy genes were observed in higher mRNA levels compared with normal cholangiocytes separated by laser capture microdissection. As shown in the results (Figure 2c), beclin1 mRNA expression was markedly increased in $85 \%$ (35 of 41) samples. The atg 5 highly expressed in about $88 \%$ (36 of 41 ) of samples (Figure 2c). IHC was performed on beclin 1 expression in 50 cases of ICC samples. As shown in Figure 2d, $28 \%$ (14 of 50) of samples presented strong expression, $48 \%$ (24 of 50) presented moderate expression and 24\% (12 of 50) showed none to weak expression. We also detected beclin 1 

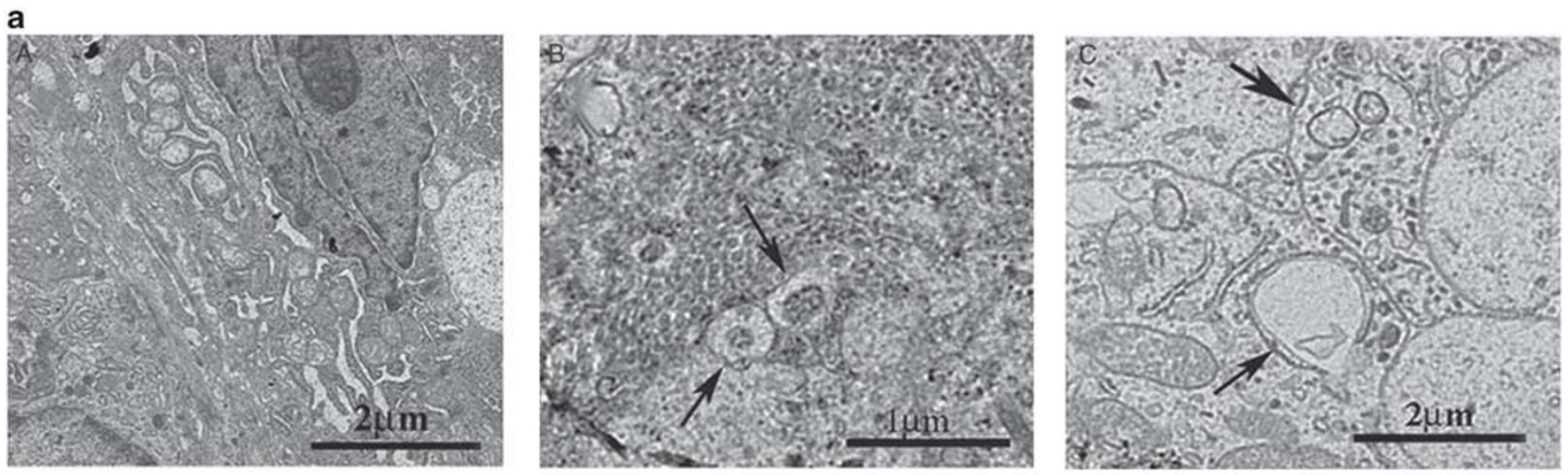

b $\quad \begin{array}{llllllllllllllllll} & 1 & 2 & 3 & 4 & 5 & 6 & 7 & 8 & 91011 & 1213141516171819202122 & 2324\end{array}$

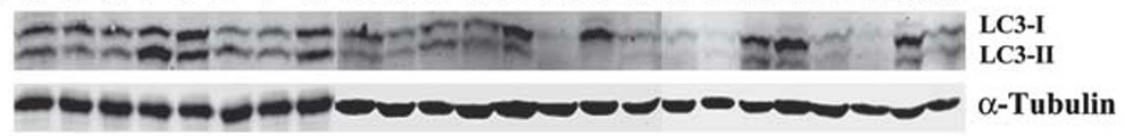

C

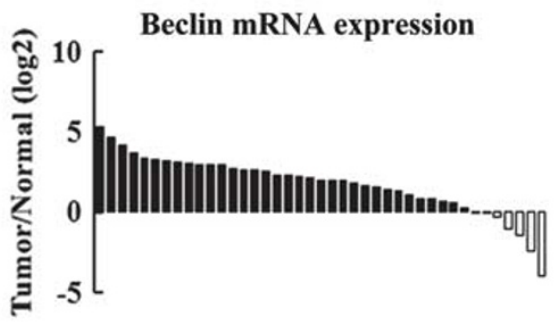

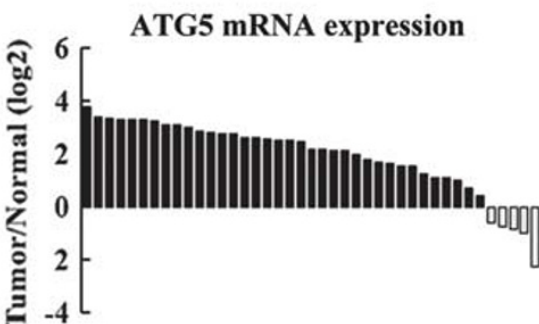

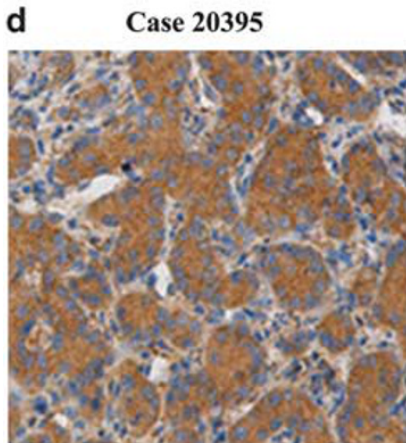

Strong (14/50)

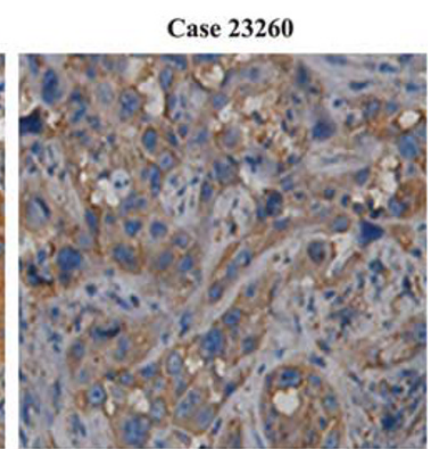

Moderate (24/50)

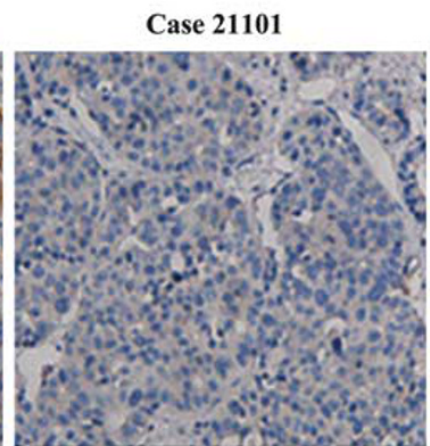

None-Weak (12/50)

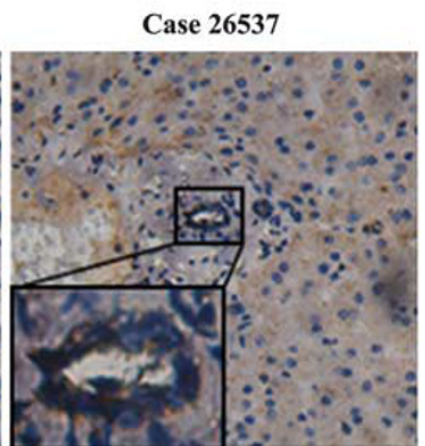

Normal bile duct

Figure 2 Autophagy is activated in clinical intrahepatic cholangiocarcinoma specimens. (a) Transmission electron microscopy analysis on ultrastructures of normal bile duct epithelium (A) and surgically resected ICC tissues (B, C). Numerous autophagic vacuoles and empty vacuoles (arrows) were observed. (b) Western blotting analysis on LC3 expression in ICC specimens. S, sample. (c) The mRNA expression of autophagy relative genes in ICC specimens. Atg 5 and beclin 1 mRAN expression levels were detected on 41 clinical ICC specimens and five cases normal bile vessel tissue obtained by laser capture microdissection. (d) IHC analysis on beclin 1 expression in 50 cases of ICC samples. Representative cases indicate strong, moderate, none to weak and normal bile duct epithelium expression of beclin 1 protein.

expression in normal liver tissues and found all the samples presented none to weak expression in bile duct epithelium (Figure 2d).

\section{Inhibition of Autophagy-Induced Apoptosis of Cholangiocarcinoma Cell Lines During Nutrient Starvation}

To examine the effect of autophagy on tumor cell survival during nutrient starvation, we observed whether inhibition of autophagy would affect tumor growth. We found that QBC939 and RBE cells showed few apoptotic cells in both cell lines during $48 \mathrm{~h}$ culture in amino-acid-deprived medium, which was detected by Hoechst33342 staining (Figure 3a and b). On the contrary, when the autophagy inhibitor, 3-MA, was applied to amino-acid-deprived medium, there were more chromatin condensation occurring in these cells (Figure 3a and b), which was also confirmed with AnnexinV and PI double staining (Figure $3 \mathrm{c}$ and $\mathrm{d}$ ). 
In mammalian, beclin1 is a part of class-III PI3K complex, which is required to recruit the Atg12-Atg5 conjugate to the preautophagosomal structure. In all, 3-MA, as an inhibitor against this conjunction at a relatively early stage, attenuates autophagy. Then, we construct the (adnovirus-delivered) AdSiRNA targeting beclin 1 to block the formation of autophagosomes. In QBC939 cells, the Adsibeclin significantly decreased the expression of beclin $1 \mathrm{mRNA}$ and protein (Figure 4a). By CCK-8 assay, we determined the proliferation of QBC cells after transfection with AdSi-beclin or AdSi-blank virus for $12 \mathrm{~h}$. The results showed that knocking down beclin 1 caused cells growing slowly compared with cells with normal expression of beclin 1 (Figure $4 \mathrm{~b}$ ). Flow cytometry revealed that $\mathrm{QBC}$ cells with downregulation of beclin 1 arrested at G2/M phase under starvation condition (Figure 4c). These results suggest that autophagy is involved in regulation of cell proliferation and cycle. We used
AnnexinV-FITC and PI staining assay to determine the apoptotic cell death under normal culture medium or EBSS starvation medium. As shown in Figure 4d, QBC cells infected with blank adenovirus showed no difference in the number of apoptoic cells in normal or EBSS medium $(4.88 \%$ vs 5.87\%). To our surprise, deletion of beclin 1 did not result in increase of apoptotic cells in cells in normal culture medium, but gave rise to more apoptotic cells when the cells were in EBSS starvation medium (5.87\% vs $11.71 \%$ ), suggesting that beclin 1 is involved in regulating cell apoptosis in starvation condition.

\section{Inhibition of Autophagy Suppressed Established Tumor Growth in Nude Mice}

To determine whether the autophagy inhibitors could serve as a therapeutic agent against cholangiocarcinoma tumor formation, 2 weeks after inoculation of the cells, DMSO or a

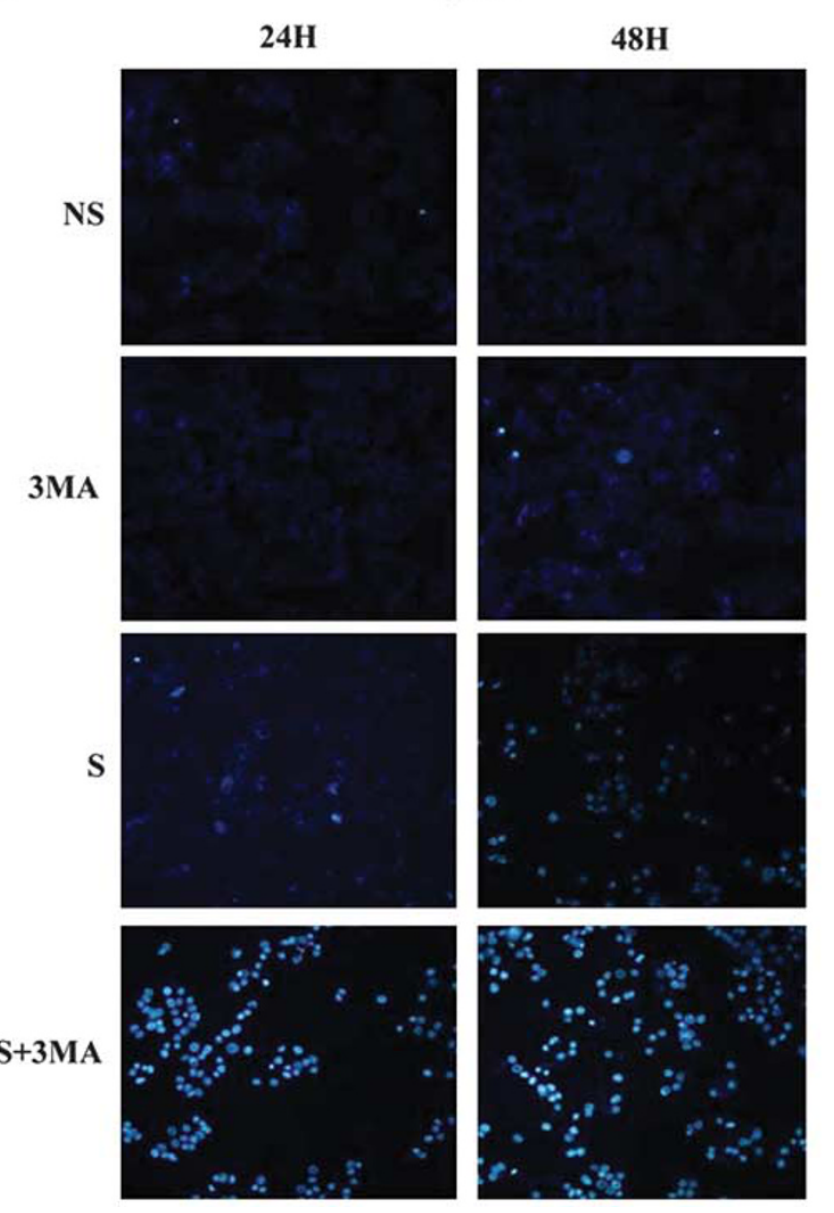

b
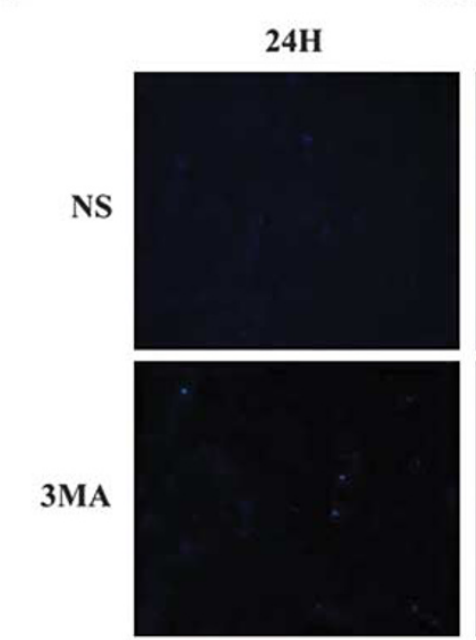

$\mathbf{S}$
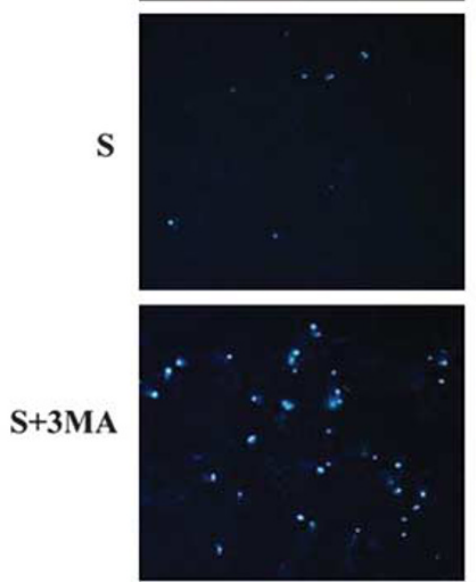
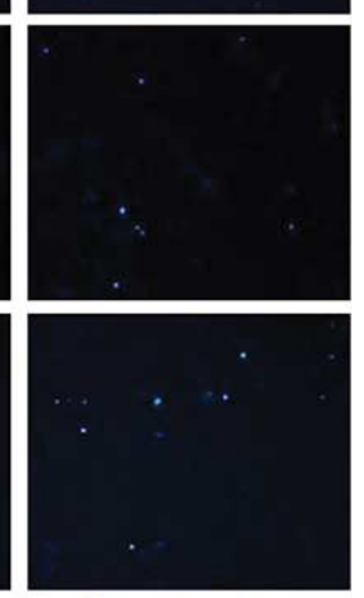

RBE
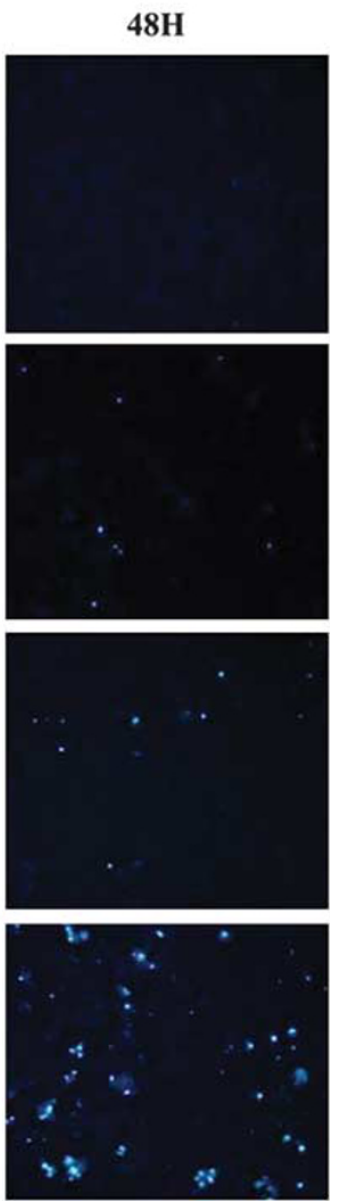

Figure 3 Inhibition of autophagy-induced apoptosis of cholangiocarcinoma cell lines during nutrient starvation. (a) QBC939 and (b) RBE cells were cultured in normal condition (NS) or starvation condition (S, incubated in EBSS) with vehicle (PBS) or $10 \mathrm{mmol} / \mathrm{l}$ of $3-\mathrm{MA}$ for $12,24,36$ and $48 \mathrm{~h}$, then stained with Hoechst 33342. Cells in apoptosis show chromatin condensation with dark Hoechst 33342-positive staining. (c, d) Blocking autophagy induced apoptosis of cholangiocarcinoma cell lines during nutrient starvation. (c) RBE and (d) QBC939 cells were cultured in EBSS with PBS or 10 mmol/l of 3-MA for 12-48 $\mathrm{h}$, then collected and double stained with FITC-conjugated AnnexinV and PI. Analysis was performed by flow cytometry.

${ }^{*} P<0.05 ;{ }^{*} P<0.01(n=3)$. 
C

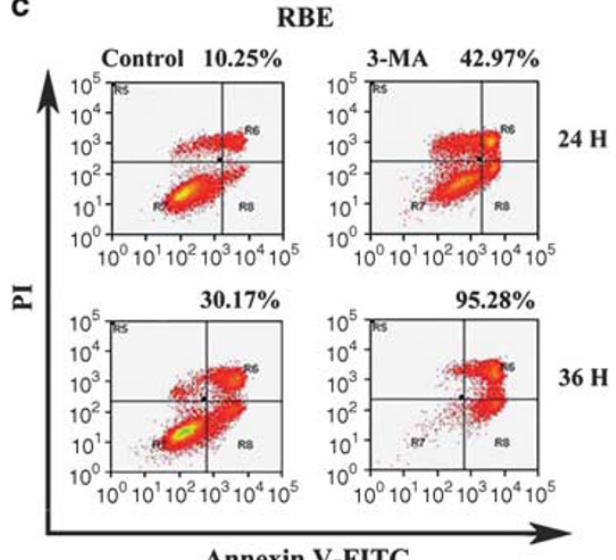

Annexin V-FITC

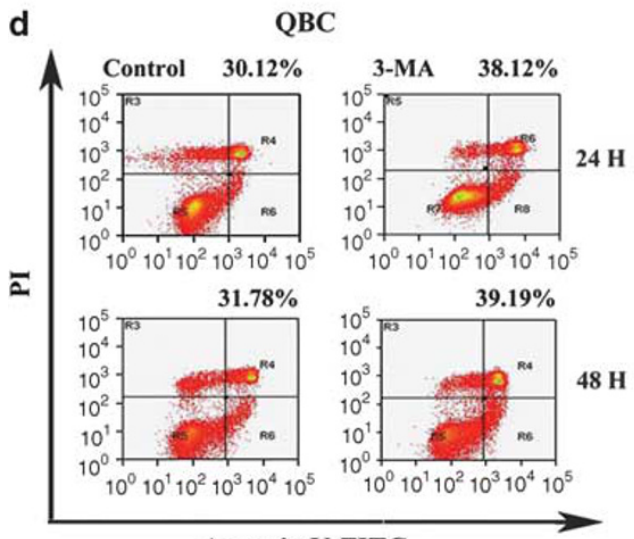

Annexin V-FITC
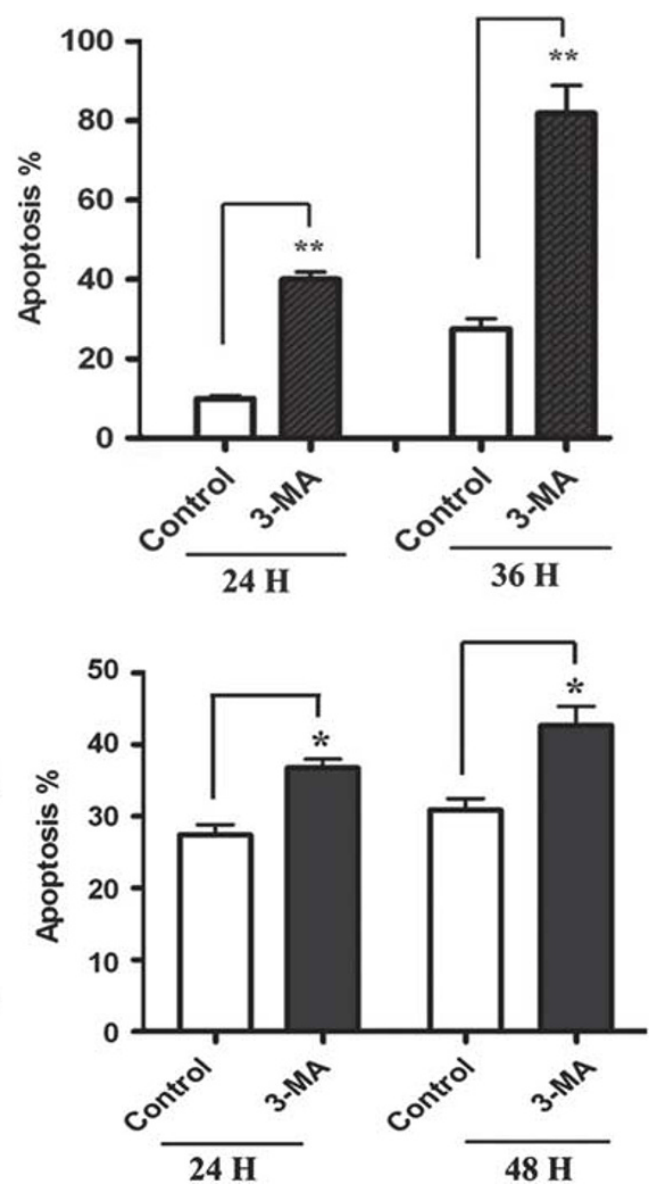

Figure 3 Continued.

wortmannin was administered. After treatment with the agent for 2 weeks, the tumor growth obviously was inhibited compared with the DMSO animal group (Figure 5a). The weight of tumors in DMSO group was almost two times than that in wortmannin group (Figure 5b). By real-time PCR assay, wortmannin treatment decreased atg5 and beclin1 expression in the QBC tumors (Figure $5 \mathrm{c}$ and $\mathrm{d}$ ). We also used AdSi-beclin or AdSi-blank virus to administer locally by intratumor injection. This kind of treatment causes significant suppression of beclin 1 expression, which was confirmed by the immunostaining on tumor slices (Figure $5 \mathrm{~g}$ ). Furthermore, we stained the tumor specimen for cholangiocyte marker CK19, as shown in Figure 5g, the xenograft tumor cells retained cholangiocytes. After treatment with AdSi-beclin, the tumor growth obviously was inhibited compared with the AdSi-blank or mock animal group (Figure 5e and f).

\section{Inhibition of Autophagy Enhances Sensitivity of Cholangiocarcinoma Cells to Chemotherapy}

Cisplatin is reported to have an additive or synergistic effect in combination with other drugs in a number of different tumor types, including biliary tract carcinoma. ${ }^{26}$ Fluorescence microscopy revealed a diffuse localization of GFP-LC3 in PBS-treated control cells. In contrast, treatment of cells with cisplatin produced a punctate pattern for GFP-LC3 fluorescence (Figure 6a), indicating that LC3-II were recruited to autophagosomes during activation of autophagy. The results were confirmed by analysis of LC3 expression in cell lysates, revealed the presence of processed LC3-II that was evident as early as $6 \mathrm{~h}$ post-treatment with doxorubicin or cisplatin and its intensity increased with longer stimulating time (Figure 6b).

In order to examine if the activated autophagy could affect the chemotherapy effects on cholangiocarcinoma cells, we detected the proliferation of cholangiocarcinoma cells in the treatment of cisplatin with or without autophagy inhibitors by CCK-8 assay. Proliferation assay showed that treatment with cisplatin alone did not inhibit proliferation of the two cholangiocarcinoma cells (Figure $6 \mathrm{c}$ and d), while treatment combined with 3-MA or wortmannin significantly suppressed the growth of cholangiocarcinoma cells. To confirm these results, we reexamined the proliferation tests by directly measuring the number of cells. As shown in Supplementary Figure, 3-MA combined with cisplatin treatment significantly inhibited cell proliferation. These results suggest that inhibition of autophagy is helpful for cisplatin-induced suppression of proliferation. 

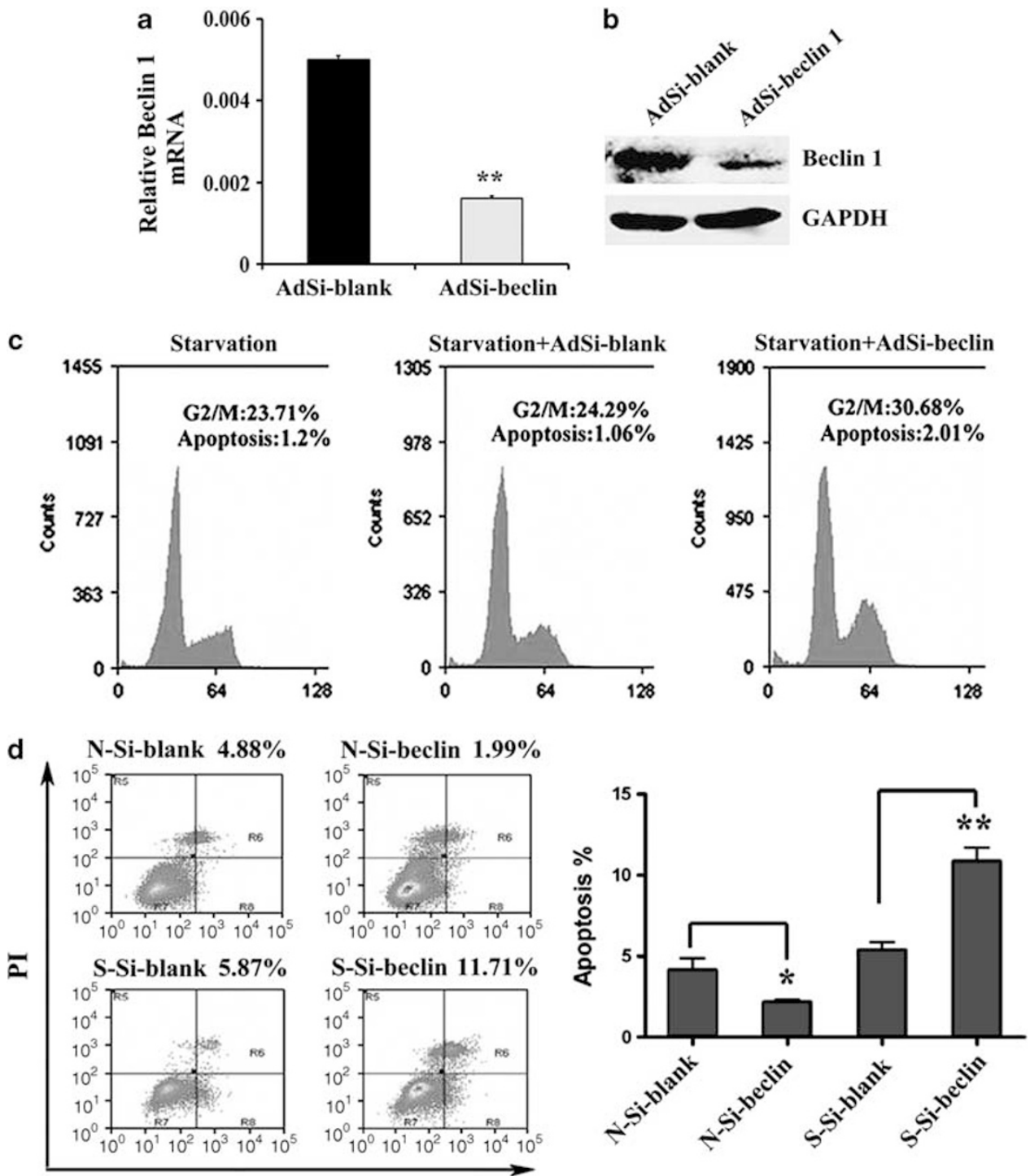

Annexin V-FITC

Figure 4 AdSiRNA targeting autophagy gene beclin 1-induced ICC cell arrest and apoptosis during nutrient starvation. (a, b) AdSi-beclin decreased beclin 1 mRNA and protein expression. (c) Deletion beclin 1 expression-induced G2/M phase arrest of QBC cells. Twelve hours after the virus infection, the cell medium was changed to EBSS incubating for another $48 \mathrm{~h}$, and then the adherent cells were collected by trypsinization and determined with flow cytometry. Three individual experiments were performed, and the cell distribution in the cell cycle was determined by standard fluorescence-activated cell sorter analysis. The cell population in G2/M phase was shown. The $x$ and $y$ axes represent DNA content and the cell number, respectively.

(d) Deletion of beclin 1 promoted cell apoptosis by starvation culture. QBC cells were infected with AdSi-beclin or AdSi-blank for $12 \mathrm{~h}$, then the supernatant were changed for EBSS or normal medium incubating for another $48 \mathrm{~h}$. Treated cells were stained and apoptosis was assessed by flow cytometry using an AnnexinV-FITC apoptosis detection kit.

We further analyzed effect of beclin 1 expression on cell cycle and apoptosis induced by cisplatin. As shown in Figure 6e, knockdown beclin induced more cells arrest at G2/M phase under cisplatin treatment. Although suppression of beclin 1 slightly reduced the number of apoptotic cells, it resulted in more dead cells by treatment with cisplatin (Figure 6f). Compared with cisplatin treatment in the cells with AdSi-blank, inhibition of beclin 1 enhanced cisplatin effect on apoptosis (17.54\% vs $6.85 \%)$.

\section{DISCUSSION}

In the present study, we demonstrate that the role of autophagy in ICC cells is important in the condition of nutrient starvation and chemotherapy. Human intrahepatic cholangiocarcinomas have shown high expression of autophagy genes and proteins.

Increasing evidence indicates that autophagy is the presence and active in various of tumor cells and promotes tumor cell survival in response to starvation, hypoxia, oxidative damage 
or other stress. ${ }^{27-30}$ Hepatitis B virus and hepatitis C virus infections, liver cirrhosis and other inflammation diseases have been examined as potential risk factors for ICC, ${ }^{31,32}$ and also potential factors for induction of autophagy. During growth of ICC, tumor cells periodically outstrip in the vasculature, resulting in narrowing blood vessels that causes nutrient starvation and low oxygen. Our results determine that nutrition starvation is able to activate formation of autophagy and expression of its associated proteins, such as LC3-II, beclin 1 . Function of autophagy is thought to be a self-digestive process that ensures lysosomal degradation of long-lived proteins and organelles to maintain cellular homeostasis, ${ }^{6}$ and may be as a protective mechanism and an indispensable physiologic reaction for cells to survive and generate nutrients and energy. ${ }^{33}$ But many studies demonstrated that persistent stress can also promote autophagic cell death. ${ }^{34,35}$ Autophagy-induced cell death eliminates damaged and harmful cells, such as cancer cells treated with anticancer reagents or the cells infected with pathogenic microorganisms. ${ }^{8,33,35}$ However, the role of autophagy in cancer remains elusive. In this paper, we put cells in a condition deprived amino acids that mimics tumor microenvironment relatively lacking of nutrition. The results appear that nutrition starvation increased autophagy formation and did not lead cells undergo apoptosis. But inhibition of autophagy promotes apoptosis, suggesting that autophagy may be supportive for development and survival of ICC cells in a state with relative lack of nutrition.

The beclin 1 gene is monoallelically deleted in $40-75 \%$ of sporadic breast, prostate and ovarian tumors. ${ }^{36-38}$ Previous studies have shown that beclin 1 can function as a negative regulator of mammary cell growth and tumorigenesis as well as in the induction of autophagy in breast cancer cells. ${ }^{39}$ Decreased expression of beclin 1 has also been demonstrated in some human cancers, including glioblastomas, ovarian cancers and esophageal cancers. ${ }^{39-41}$ However, increased expression of beclin 1 has been reported in colorectal and gastric cancer cells as compared with the normal counterparts. ${ }^{42}$ In this study, we found that beclin 1 mRNA was marked highly expression in $85 \%$ clinical ICC samples and $76 \%$ cases showed high protein expression. These discrepant results suggest that beclin 1 has different expression pattern in different tissues.

Since option of chemotherapy treatment for cholangiocarcinoma is limited, conventional chemotherapy and radiation therapy to date have been proved to be ineffective in improving long-term survival. Currently, complete resection of the tumor is the only best choice for long-term survival. Unfortunately, the vast majority of patients with cholangiocarcinoma don't have optimal situation for curative surgery when diagnosis is confirmed. Patients with resection
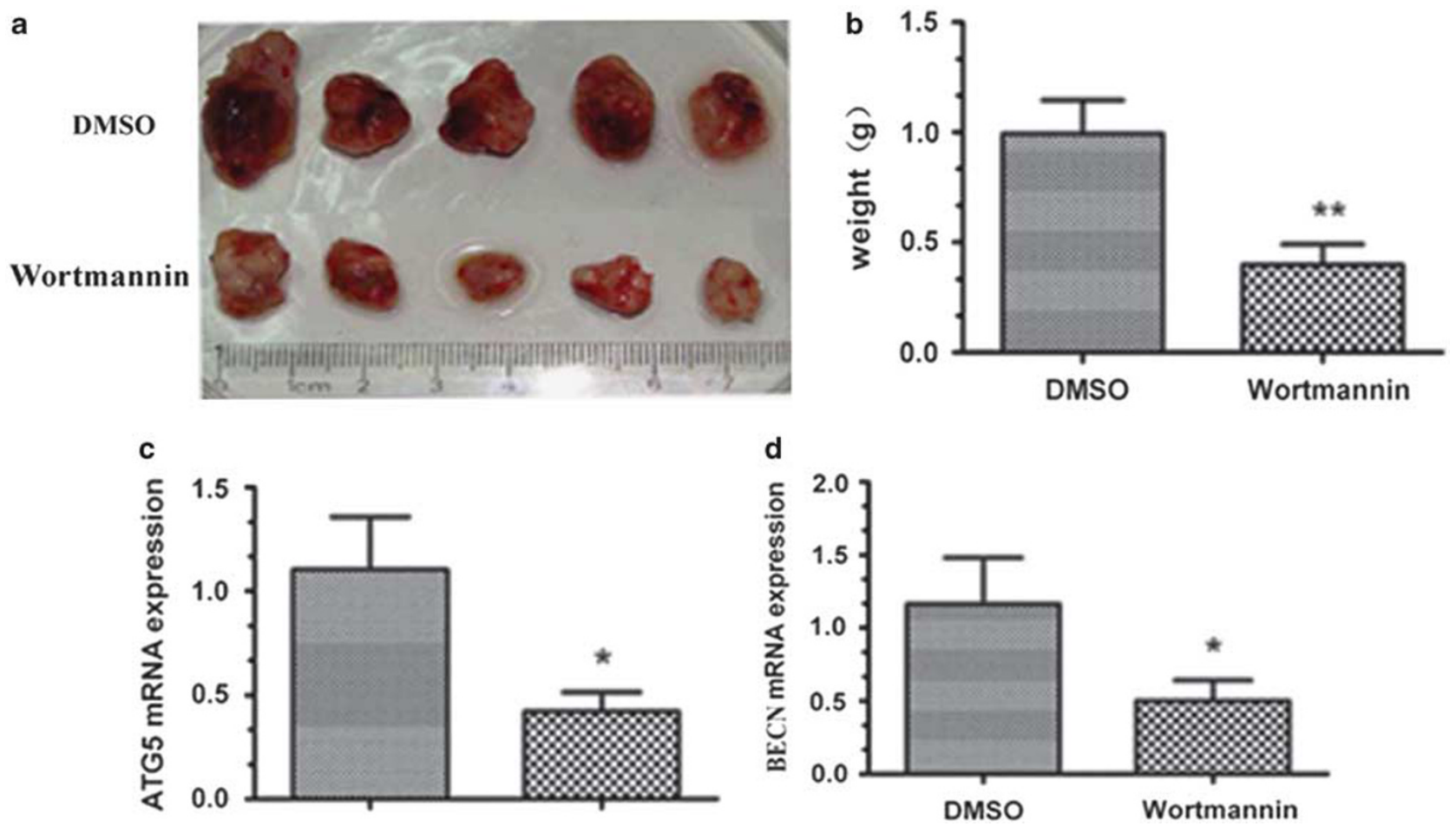

Figure 5 Inhibition of autophagy suppressed established tumor growth in nude mice. (a) Nude mice bearing established QBC939 tumors were given injections of either vehicle control DMSO or wortmannin $(2 \mathrm{mg} / \mathrm{kg}$ ). After 10 days, tumors were excised. (b) Tumors were weighted at the time of animal killing. Autophagy-related genes ATG5 (c) and beclin1 (d) mRNA expression were detected by real-time PCR. (e) Established tumors were treated with AdSibeclin or AdSi-blank for 2 weeks. (f) Tumors were weighted at the time of killing. (g) Tumor slices were tested by beclin 1 and CK19 staining after ad-virus treatment. ${ }^{\star} P<0.05 ;{ }^{*} P<0.01(n=5)$. 
e
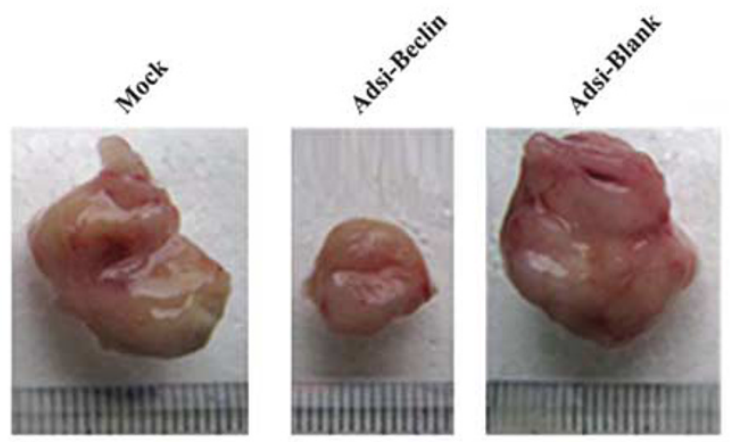

g

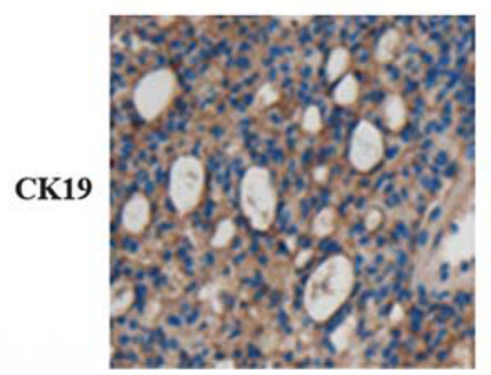

Adsi-Beclin
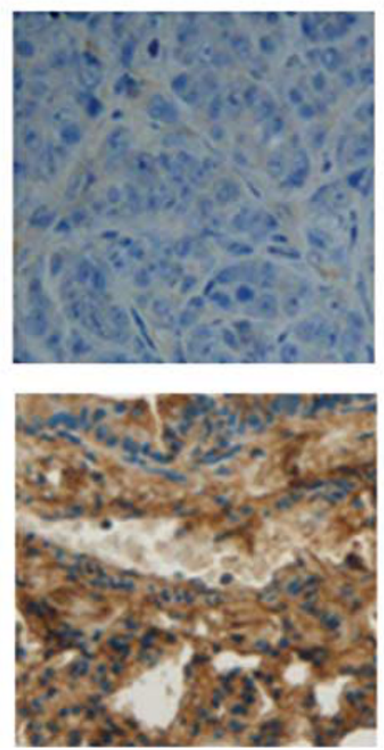

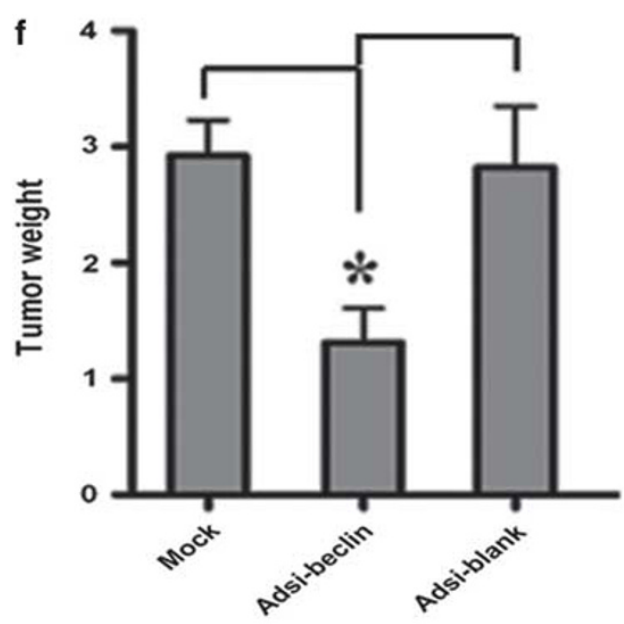

Adsi-Blank
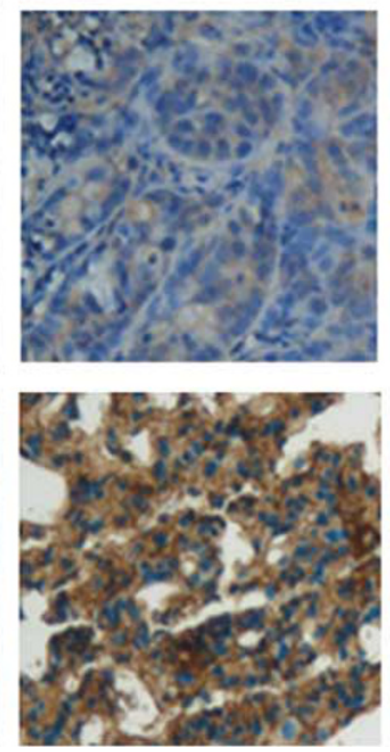

Normal bile duct

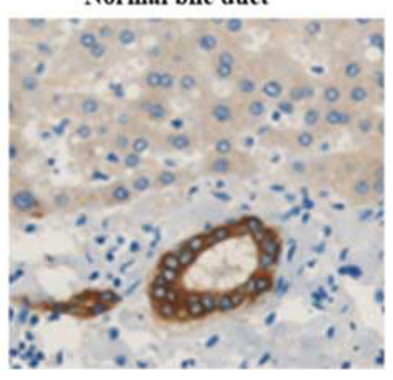

Figure 5 Continued.

generally have the higher recurrence rate. ${ }^{43,44}$ In addition, chemotherapy also induces acquired resistance that has been one of the most important clinical problems. ${ }^{45,46}$ At such a circumstance, there is now a real and urgent need to focus on developing novel therapeutic strategies for cholangiocarcinoma that would impact in a significant way on clinical outcome. We used cisplatin and doxorubicin, the two clinically highly relevant anticancer drugs, to stimulate cholangiocarcinoma cells and observed that autophagy was activated. Cisplatin is a clinically highly relevant anticancer drug used for the treatment of many kinds of cancers. The major mechanism underlying its antitumor activity has been ascribed to the induction of DNA damage by platinum compounds. ${ }^{47}$ Doxorubicin is also known to interact with DNA by intercalation and inhibition of macromolecular biosynthesis. ${ }^{48}$ Question is whether the activated autophagy contributes to chemotherapy resistance? By autophagy inhibitor and adenovirus-delivered siRNA for autophagy protein, beclin 1, to block autophagy activation, we found that these treatments promote sensitivity of the cells to chemotherapy drug, resulting in more apoptotic cells than control. This study is the first time to demonstrate that DNA-damaging chemotherapeutic drugs, cisplatin and doxorubicin, activate an autophagic stress response in the cholangiocarcinoma cells. This work also showed that knocking down of proteins, such as beclin 1, is critical for autophagosome formation, and may lead to apoptosis occurring in these cells.

In conclusion, our paper demonstrates that nutrient starvation induces autophagy activation that promotes xenograft tumor formation of cholangiocarcinoma cells. Inhibition of autophagy by autophagy inhibitor or siRNA, ICC cells show inhibition of proliferation and increase of apoptosis during 

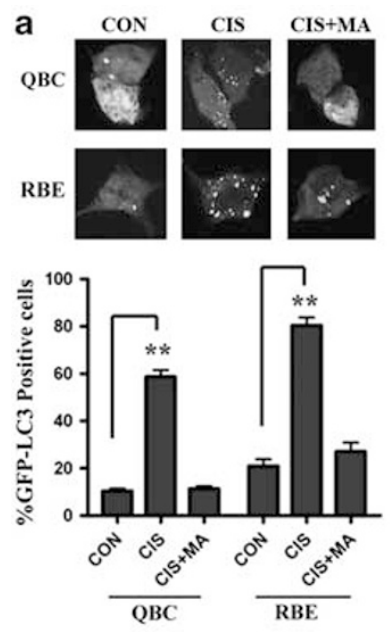

b
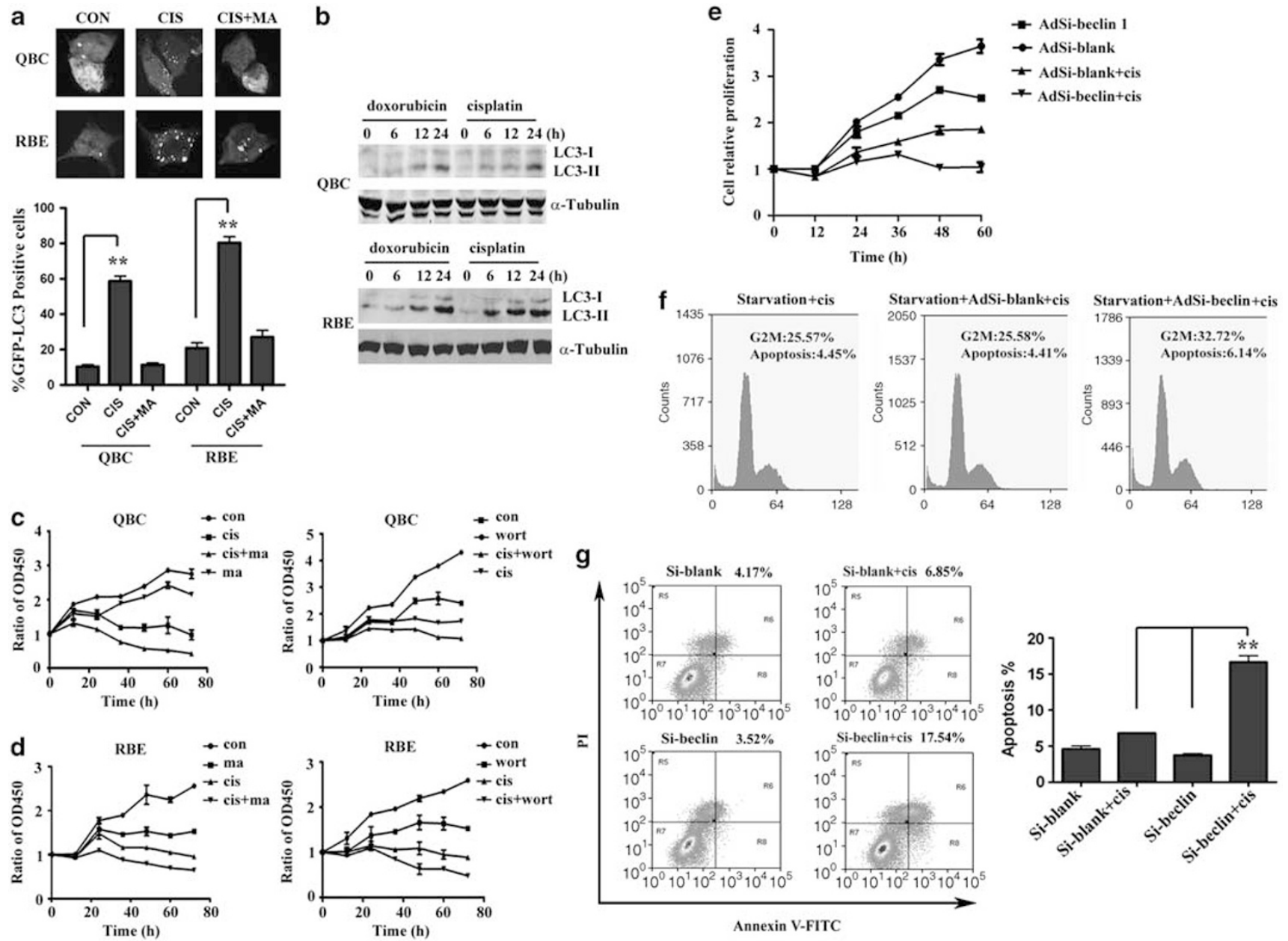

$\overline{2}$
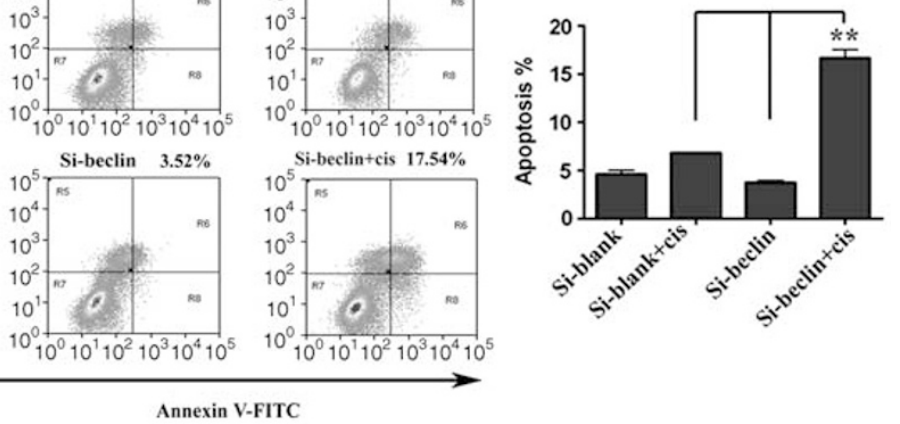

Figure 6 Inhibition of autophagy enhances chemotherapy sensitivity. (a) Representative confocal images of GFP-LC3 staining on cells under cisplatin treatment and quantitation of the GFP-LC3-positive cells with the GFP-LC3 dots in the two cell lines. Cells treated with cisplatin or cisplatin combined with 3MA for $12 \mathrm{~h}$ in normal culture condition were observed with the confocal fluorescent microscope. (b) Western blot analysis of LC3 expression on cells with chemotherapy treatment. The QBC and RBE cells were treated with doxorubicin $(10 \mu \mathrm{g} / \mathrm{ml})$ or cisplatin $(6 \mu \mathrm{g} / \mathrm{ml})$ for indicated time. Then the whole-cell lysates were harvested and subjected to western blotting analysis. (c, d) Inhibition of autophagy enhances chemotherapy sensitivity. QBC and RBE cells were seeded at $5 \times 10^{3}$ cells per well $(0.2 \mathrm{ml})$ in 96 -well plates and incubated overnight at $37^{\circ} \mathrm{C}$. After exposure to cisplatin $(6 \mu \mathrm{g} / \mathrm{ml})$ or cisplatin combined with $3-$ MA $(10 \mathrm{mmol} / \mathrm{l})$ or wortmannin $(5 \mu \mathrm{mol} / \mathrm{l})$ for $12-72 \mathrm{~h}$, cell viability was assessed at indicated time by Cell Counting kit-8. (e) Knockdown beclin 1 suppressed QBC939 cells proliferation and increased cell sensitivity to cisplatin. QBC cells were infected with AdSi-beclin or AdSi-blank virus for $12 \mathrm{~h}$, treated with or without cisplatin, and then the cells proliferation was determined by CCK-8 for up to $60 \mathrm{~h}$. (f) Deletion beclin 1 induced G2/M phase arrest of QBC cells treated with cisplatin. (g) QBC cells were infected as mentioned above, and then were treated with cisplatin $(6 \mu \mathrm{g} / \mathrm{ml})$ for $48 \mathrm{~h}$. The cells were stained and apoptosis was assessed by flow cytometry. ${ }^{\star} P<0.05 ;{ }^{*} P<0.01(n=3)$.

nutrient starvation. Downregulation of beclin 1 sensitizes these cells to cytotoxic agents and helps to enhance the therapeutic activity of DNA-damage drugs toward ICC.

Supplementary Information accompanies the paper on the Laboratory Investigation website (http://www.laboratoryinvestigation.org)

\section{ACKNOWLEDGEMENTS}

We thank Dr Mujun Zhao for kindly providing the plasmids. We are also grateful to Linna Guo for the helpful technical assistance. Research was supported by grants from National Natural Science Foundation of China (81001075, 30530790, 30620130434 and 09ZR1400800) and China Key Basic Research Program Grant (2007CB914502).

\section{DISCLOSURE/CONFLICT OF INTEREST}

The authors declare no conflict of interest.

1. Endo I, Gonen M, Yopp AC, et al. Intrahepatic cholangiocarcinoma: rising frequency, improved survival, and determinants of outcome after resection. Ann Surg 2008;248:84-96.

2. Nathan $\mathrm{H}$, Aloia TA, Vauthey JN, et al. A proposed staging system for intrahepatic cholangiocarcinoma. Ann Surg Oncol 2009;16:14-22.

3. Briggs $C D$, Neal $C P$, Mann $C D$, et al. Prognostic molecular markers in cholangiocarcinoma: a systematic review. Eur J Cancer 2009:45:33-47.

4. Khan SA, Thomas HC, Davidson BR, et al. Cholangiocarcinoma. Lancet 2005;366:1303-1314.

5. Anderson CD, Pinson CW, Berlin J, et al. Diagnosis and treatment of cholangiocarcinoma. Oncologist 2004;9:43-57. 
6. Levine B, Klionsky DJ. Development by self-digestion: molecular mechanisms and biological functions of autophagy. Dev Cell 2004;6:463-477.

7. Levine B, Kroemer G. Autophagy in the pathogenesis of disease. Cell 2008;132:27-42.

8. White E, Karp C, Strohecker AM, et al. Role of autophagy in suppression of inflammation and cancer. Curr Opin Cell Biol 2010;22:212-217.

9. Klionsky DJ, Emr SD. Autophagy as a regulated pathway of cellular degradation. Science 2000;290:1717-1721.

10. Huang X, Ke A, Shi G, et al. Overexpression of CD151 as an adverse marker for intrahepatic cholangiocarcinoma patients. Cancer 2010 116:5440-5451.

11. Hasita $\mathrm{H}$, Komohara $\mathrm{Y}$, Okabe $\mathrm{H}$, et al. Significance of alternatively activated macrophages in patients with intrahepatic cholangiocarcinoma. Cancer Sci 2010;101:1913-1919.

12. Zhang K, Wang D, Zhang S, et al. The E-cadherin repressor slug and progression of human extrahepatic hilar cholangiocarcinoma. J Exp Clin Cancer Res 2010;29:88.

13. Abedin M, Wang D, McDonnell M, et al. Autophagy delays apoptotic death in breast cancer cells following DNA damage. Cell Death Differ 2007;14:500-510.

14. Sato K, Tsuchihara K, Fujii S, et al. Autophagy is activated in colorectal cancer cells and contributes to the tolerance to nutrient deprivation. Cancer Res 2007;67:9677-9684.

15. Schulze-Bergkamen H, Fleischer B, Schuchmann M, et al. Suppression of Mcl-1 via RNA interference sensitizes human hepatocellular carcinoma cells towards apoptosis induction. BMC Cancer 2006;6:232.

16. Akar U, Chaves-Reyez A, Barria $\mathrm{M}$, et al. Silencing of $\mathrm{BCl}-2$ expression by small interfering RNA induces autophagic cell death in MCF-7 breast cancer cells. Autophagy 2008;4:669-679.

17. Chen $\mathrm{L}$, Yan $\mathrm{H}$, Yang $\mathrm{W}$, et al. The role of microRNA expression pattern in human intrahepatic cholangiocarcinoma. J Hepatol 2009;50:358-369.

18. Li H, Fu X, Chen Y, et al. Use of adenovirus-delivered siRNA to target oncoprotein p28GANK in hepatocellular carcinoma. Gastroenterology 2005;128:2029-2041.

19. Dong L, Kong $\mathrm{X}$, Yan H, et al. Signal regulatory protein alpha negatively regulates both TLR3 and cytoplasmic pathways in type I interferon induction. Mol Immunol 2008;45:3025-3035.

20. Wen W, Ding J, Sun W, et al. Suppression of cyclin D1 by hypoxiainducible factor-1 via direct mechanism inhibits the proliferation and 5-fluorouracil-induced apoptosis of A549 cells. Cancer Res 2010;70: 2010-2019.

21. Suzuk A, Kusakai G, Kishimoto A, et al. ARK5 suppresses the cell death induced by nutrient starvation and death receptors via inhibition of caspase 8 activation, but not by chemotherapeutic agents or UV irradiation. Oncogene 2003:22:6177-6182.

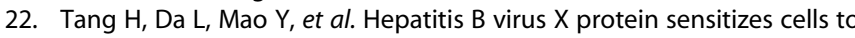
starvation-induced autophagy via up-regulation of beclin 1 expression. Hepatology 2009;49:60-71.

23. Zhang $\mathrm{K}$, Chen $\mathrm{D}$, Wang $\mathrm{X}$, et al. RNA interference targeting slug increases cholangiocarcinoma cell sensitivity to cisplatin via upregulating PUMA. Int J Mol Sci 2011;12:385-400.

24. Schultz $\mathrm{R}$, Merriman $\mathrm{R}$, Andis $\mathrm{S}$, et al. In vitro and in vivo antitumor activity of the phosphatidylinositol-3-kinase inhibitor, wortmannin. Anticancer Res 1995;15:1135-1139.

25. Sylvia S, Ming-Sound T, Trudey N, et al. Wortmannin inhibits PKB/Akt phosphorylation and promotes gemcitabine antitumor activity in orthotopic human pancreatic cancer xenografts in immunodeficient mice. Clin Cancer Res 2001;7:3269-3275.

26. Ducreux M, Van Cutsem E, Van Laethem JL, et al. A randomised phase II trial of weekly high-dose 5-fluorouracil with and without folinic acid and cisplatin in patients with advanced biliary tract carcinoma: results of the 40955 EORTC trial. Eur J Cancer 2005;41:398-403.
27. Longo L, Platini F, Scardino A, et al. Autophagy inhibition enhances anthocyanin-induced apoptosis in hepatocellular carcinoma. Mol Cancer Ther 2008:7:2476-2485.

28. Mathew R, Karantza-Wadsworth V, White E. Role of autophagy in cancer. Nat Rev Cancer 2007;7:961-967.

29. Karantza-Wadsworth V, Patel S, Kravchuk O, et al. Autophagy mitigates metabolic stress and genome damage in mammary tumorigenesis. Genes Dev 2007;21:1621-1635.

30. Sato K, Tsuchihara K, Fujii S, et al. Autophagy is activated in colorectal cancer cells and contributes to the tolerance to nutrient deprivation. Cancer Res 2007;67:9677-9684.

31. Donato F, Gelatti U, Tagger A, et al. Intrahepatic cholangiocarcinoma and hepatitis C and B virus infection, alcohol intake, and hepatolithiasis: a case-control study in Italy. Cancer Causes Control 2001;12:959-964.

32. Kobayashi $\mathrm{M}$, Ikeda $\mathrm{K}$, Saitoh $\mathrm{S}$, et al. Incidence of primary cholangiocellular carcinoma of the liver in Japanese patients with hepatitis C virus-related cirrhosis. Cancer 2000;88:2471-2477.

33. Kirkegaard K, Taylor MP, Jackson WT. Cellular autophagy: surrender, avoidance and subversion by microorganisms. Nat Rev Microbiol 2004;2:301-314.

34. Kundu M, Thompson CB. Autophagy: basic principles and relevance to disease. Annu Rev Pathol 2008:3:427-455.

35. Kondo $Y$, Kanzawa T, Sawaya R, et al. The role of autophagy in cancer development and response to therapy. Nat Rev Cancer 2005;5: 726-734.

36. Cliby W, Ritland S, Hartmann L, et al. Human epithelial ovarian cancer allelotype. Cancer Res 1993;53:2393-2398.

37. Saito $\mathrm{H}$, Inazawa J, Saito $\mathrm{S}$, et al. Detailed deletion mapping of chromosome 17q in ovarian and breast cancers: 2-cM region on $17 q 21.3$ often and commonly deleted in tumors. Cancer Res 1993;53:3382-3385.

38. Gao X, Zacharek A, Salkowski A, et al. Loss of heterozygosity of the BRCA1 and other loci on chromosome 17q in human prostate cancer. Cancer Res 1995;55:1002-1005.

39. Miracco C, Cosci E, Oliveri G, et al. Protein and mRNA expression of autophagy gene Beclin 1 in human brain tumours. Int J Oncol 2007;30:429-436.

40. Chen Y, Lu Y, Lu C, et al. Beclin-1 expression is a predictor of clinical outcome in patients with esophageal squamous cell carcinoma and correlated to hypoxia-inducible factor (HIF)-1alpha expression. Pathol Oncol Res 2009;15:487-493.

41. Shen Y, Li DD, Wang LL, et al. Decreased expression of autophagyrelated proteins in malignant epithelial ovarian cancer. Autophagy 2008;4:1067-1068

42. Ahn $\mathrm{CH}$, Jeong EG, Lee JW, et al. Expression of beclin-1, an autophagyrelated protein, in gastric and colorectal cancers. APMIS 2007;115: 1344-1349.

43. Tamandl D, Herberger B, Gruenberger B, et al. Influence of hepatic resection margin on recurrence and survival in intrahepatic cholangiocarcinoma. Ann Surg Oncol 2008;15:2787-2794.

44. Yedibela S, Demir R, Zhang W, et al. Surgical treatment of massforming intrahepatic cholangiocarcinoma: an 11-year western singlecenter experience in 107 patients. Ann Surg Oncol 2009;16:404-412.

45. Kartalou M, Essigmann JM. Mechanisms of resistance to cisplatin. Mutat Res 2001;478:23-43.

46. Siddik ZH. Cisplatin: mode of cytotoxic action and molecular basis of resistance. Oncogene 2003;22:7265-7279.

47. Rabik C, Dolan M. Molecular mechanisms of resistance and toxicity associated with platinating agents. Cancer Treat Rev 2007;33:9-23.

48. Fornari F, Randolph J, Yalowich J, et al. Interference by doxorubicin with DNA unwinding in MCF-7 breast tumor cells. Mol Pharmacol 1994:45:649-656. 